
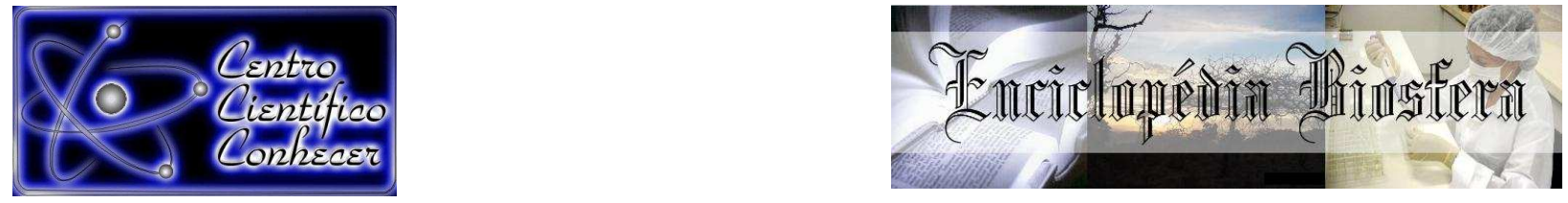

\title{
DESENVOLVIMENTO DE MUDAS DE KALANCHOE SOB DIFERENTES NÍVEIS CRESCENTES DE CONDUTIVIDADE ELÉTRICA
}

\author{
Jéssica Soares Pereira ${ }^{1}$; Luciana Ferreira de Lima $^{2}$; Rosana Martins Portela ${ }^{3}$; Adriely \\ Fernandes Vieira ${ }^{4}$; Roberto Jun Takane ${ }^{5}$.
}

1 Pós-Graduando em Agronomia - Fitotecnia da Universidade Federal do Ceará, Fortaleza - Brasil. (jessicasoares@alu.ufc.br)

2. Engenheira Agrônoma - voluntária do Projeto CEFLOR - Universidade Federal do Ceará, Fortaleza - Brasil.

3. Engenheira Agrônoma - voluntária do Projeto CEFLOR - Universidade Federal do

Ceará, Fortaleza - Brasil.

4. Pós-Graduando em Agronomia - Fitotecnia da Universidade Federal do Ceará, Fortaleza - Brasil.

5. Professor do Departamento de Fitotecnia - Universidade Federal do Ceará, Fortaleza - Brasil.

\section{Recebido em: 08/09/2015 - Aprovado em: 14/11/2015 - Publicado em: 01/12/2015 DOI: http://dx.doi.org/10.18677/Enciclopedia_Biosfera_2015_132}

\begin{abstract}
RESUMO
O Kalanchoe (k. marmorata), com especialidade de sobreviver em ambientes secos, ser de fácil propagação e cultivo se destaca no setor de plantas ornamentais. Diante das condições do semiárido nordestino e a qualidade da água no crescimento e desenvolvimentos das culturas, o trabalho teve como objetivo avaliar o efeito de diferentes níveis de salinidade da água de irrigação no desenvolvimento de mudas de Kalanchoe marmorata. O experimento foi conduzido em casa de vegetação e distribuído em delineamento inteiramente casualizado (DIC) com 5 repetições de 4 plantas cada. Os tratamentos consistiram de diferentes condutividades elétricas em

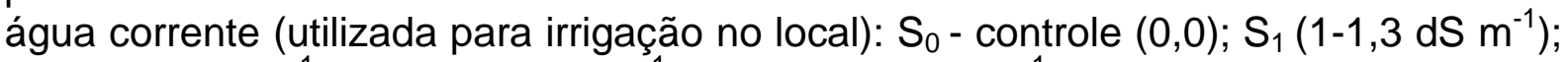

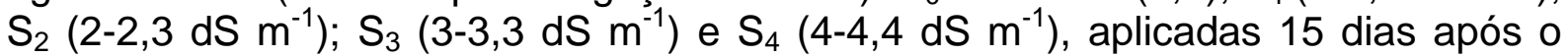
transplantio. Após 90 dias, foram iniciadas as avaliações: Altura das plantas (ALT); Comprimento da raiz (CR); Peso Total da planta (PT); Matéria Fresca e Seca da parte aérea e da raiz respectivamente (MFPA/MFRA e MSPA/MSRA); Diâmetro da

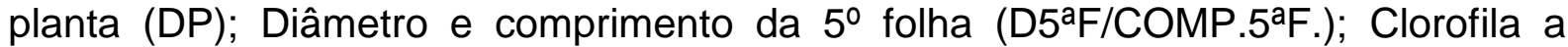
(Chla) e Clorofila b (Chlb); Peso foliar total (PFT), Número de folhas (NF). Todas as variáveis com exceção da PT, do PFT MFPA e da MSPA foram influenciadas pelas doses salinas $(\mathrm{NaCl})$. As plantas que não receberam aplicação da solução salina obtiveram os maiores valores médios observados. Nas condições do experimento as mudas Kalanchoe (K. laetivirens), responderam de forma negativa as soluções salinas utilizadas.
\end{abstract}

PALAVRAS-CHAVE: Condutividade elétrica; Crescimento; Plantas ornamentais; Vigor. 


\title{
KALANCHOE SEEDLINGS DEVELOPMENT UNDER DIFFERENT LEVELS OF ELECTRICAL CONDUCTIVITY GROWING
}

\begin{abstract}
The Kalanchoe ( $\mathrm{k}$. Marmorata) with specialty survive in dry environments, be easy propagation and cultivation stands out in the ornamental plants sector. In the face of the northeastern semi-arid and water quality conditions in the growth and development of crops, the study aimed to evaluate the effect of different levels of irrigation water salinity in the development of Kalanchoe marmorata seedlings. The experiment was conducted in a greenhouse and distributed in a completely randomized design (CRD) with 5 replicates of 4 plants each. The treatments consisted of different electrical conductivity in running water (used for irrigation on site): S0 - control (0.0); S1 (1-1.3 dS m-1); S2 (2-2.3 dS m-1); S3 (3 to $3.3 \mathrm{dS} \mathrm{m-1)}$ and S4 (4 to $4.4 \mathrm{dS} \mathrm{m}-1$ ) applied 15 days after transplanting. Plant height (ALT),: after 90 days, evaluations were initiated Root length $(\mathrm{CR})$; Total weight of the plant (PT); Fresh and dry shoot and root respectively (MFPA / MFRA and MSPA / MSRA); Plant diameter (DP); Diameter and length of the sheet 5 (D5 $\mathrm{F} /$ COMP.5 $\mathrm{F}$.); Chlorophyll a (Chla) and chlorophyll b (Chlb); Total leaf weight (PFT), leaf number (NF). All variables except for the PT, the PFT MFPA and MSPA were influenced by saline doses $(\mathrm{NaCl})$. Plants not received application of saline solution had the highest average figures. The experimental conditions the seedlings Kalanchoe (K. laetivirens) responded negatively saline solutions used.
\end{abstract}

KEYWORDS: Ornamental plants; Electrical conductivity; growth; Force.

\section{INTRODUÇÃO}

O mercado da floricultura teve um incremento na produtividade nos últimos tempos, onde segundo TAKANE et al., (2009) é principalmente em decorrência do uso de novas tecnologias associadas ao surgimento de novas espécies e variedades de flores e plantas que se tornaram acessíveis ao mercado consumidor.

A atividade da cadeia de flores e plantas ornamentais cresce cada vez mais, e movimenta um mercado que se estrutura e abre novas possibilidades de investimentos no setor. Diante disso KAMPF (2005) ressalta que atualmente, novas técnicas vêm sendo empregadas a fim de expandir conhecimentos e preservar o ambiente, onde se iniciou um processo de evolução de busca por novas tecnologias, a fim de aumentar a competição e a renda dessa atividade.

A floricultura é uma atividade que de acordo com KAMPF (2000) além de seu indiscutível papel econômico, exerce importantes funções sociais, culturais e ecológicas. Na atualidade as buscas pelos produtores que atuam diretamente nessa atividade é a opção de trabalhar com espécies que além de possibilitar para um ambiente uma ornamentação característica, rústica e duradoura, possam ter tratos culturais e manejo acessíveis para o consumidor, propriedades pelas quais podem ser uma chave para abertura de novos investimentos no setor de plantas ornamentais, visto as problemáticas ambientais presentes principalmente nas atividades agrícolas.

A atividade contabiliza mais de oito mil produtores, dos quais $98 \%$ são pequenos e médios, cultivando uma área de cerca de 11.800 mil hectares por ano, em mais de 400 municípios do Brasil, viabilizando novas oportunidades de negócios e de inclusão comercial competitiva, eficiente e sustentável para os polos de produção em todo o país (IBRAFLOR, 2013). 
O Kalanchoe, que é um dos gêneros de importância da família Crassulaceae, que apresenta muitas espécies de valor ornamental, onde o Kalanchoe marmorata destaca-se devido a sua facilidade de propagação e a beleza de suas formas, como a coloração verde forte presente nas folhas (LESSA, 2004). De forma geral as espécies de Kalanchoe são de fácil cultivo, porém existem poucos registros da melhor forma de cultivo e sobre até que condições restritas de hábitat e necessidade de água essas espécies podem suportar. MEDEIROS et al., (2003) acrescentaram que no ramo da floricultura, a literatura sobre a necessidade hídrica ainda é considerada escassa, necessitando assim de estudos relacionados à cultura, evitando possíveis desperdícios.

Em outra abordagem o mesmo autor enfatiza que a escassez dos recursos hídricos nas regiões áridas e semiáridas envolve aspectos diversos, causando restrições de uso para o consumo humano, animal e também para irrigação. Outro fato que NEVES et al., (2009) abordam é o fato que nessas regiões é comum à ocorrência de fontes de água com elevada concentração de sais principalmente sódio, que reduzem a qualidade desse recurso tão importante e utilizado na agricultura.

A irrigação, de acordo com BUSTAMANTE (2009) pode se constituir numa poderosa ferramenta para a agricultura no semiárido, onde apesar dos desafios suas potencialidades já são reconhecidas por boa parte do mundo, especialmente aqueles locais que estão próximos a grandes reservatórios de água de boa qualidade.

Os sais, segundo OLIVEIRA et al., (2010) desempenham efeitos das mais variadas formas sobre o desenvolvimento das plantas ao ponto de limitarem a produção e produtividade das culturas. Diante dessas informações, o pesquisador atribui a muitas espécies a capacidade de sobreviverem ao estresse salino, através de vários mecanismos bioquímicos e fisiológicos.

A exploração de respostas agrícolas, segundo SANTOS JÚNIOR et al., (2011) têm sido considerada como alternativa para o investimento no aproveitamento de águas salobras na região semiárida, uma vez que é inexplorada a extensa reserva hídrica dos subsolos dessa região.

Diante do interesse paisagístico pelo cultivo do Kalanchoe através da importância e influência da qualidade da água no crescimento e desenvolvimentos das culturas, principalmente quando se refere às condições de semiárido nordestino, o trabalho teve como objetivo avaliar o efeito de diferentes níveis de condutividade elétrica da água de irrigação sobre o desenvolvimento de plântulas de Kalanchoe marmorata para produção comercial de plantas ornamentais.

\section{MATERIAL E MÉTODOS}

O experimento foi desenvolvido na Universidade Federal do Ceará - UFC, Campus do Pici, Fortaleza - CE, localizada à longitude de 37\%48' W, latitude 336' S e altitude aproximada de $21 \mathrm{~m}$. Segundo KÖPPEN (1948), o clima é do tipo Aw', tropical chuvoso, com temperatura e precipitação média anual de $26,3^{\circ} \mathrm{e} 1.448 \mathrm{~mm}$, respectivamente. $O$ ensaio foi conduzido no período de setembro a dezembro de 2014, no Orquidário localizado na Horta Didática do Departamento de Fitotecnia da UFC. A casa de vegetação é coberta com plástico leitoso, difusor de 150 micras.

A coleta da espécie de Kalanchoe ( $K$. marmorata) foi realizada no Orquidário, a partir de plantas adultas que se encontravam neste local, no estágio reprodutivo com brotos de propagação nas laterais das folhas mais velhas. Tais brotos foram 
coletados no dia 05 de setembro de 2014, e colocados à sombra por um período de 24 horas, permanecendo em bom estado até o momento do transplantio. Após esse período foram transplantados em vasos plásticos em substrato de pó de coco umedecido. Após isso, os vasos foram acondicionados sobre as bancadas no interior da casa de vegetação.

No dia 6 de setembro de 2014, as mudas foram transplantadas para vasos plásticos, com altura de $5,0 \mathrm{~cm}$; diâmetro superior de $5,8 \mathrm{~cm}$; diâmetro inferior de 4,2 $\mathrm{cm}$ e volume de $90 \mathrm{~mL}$. No total do experimento utilizaram-se cinquenta vasos, com duas mudas de Kalanchoe/vaso.

$\mathrm{O}$ delineamento experimental utilizado foi o inteiramente casualizado (DIC), com cinco repetições de 4 plantas cada. Os tratamentos consistiram de diferentes condutividades elétricas em água corrente (utilizada para irrigação no local): $\mathrm{S}_{0}$ controle $(0,0) ; \mathrm{S}_{1}\left(1-1,3 \mathrm{dS} \mathrm{m}^{-1}\right) ; \mathrm{S}_{2}\left(2-2,3 \mathrm{dS} \mathrm{m}^{-1}\right) ; \mathrm{S}_{3}\left(3-3,3 \mathrm{dS} \mathrm{m}^{-1}\right)$ e $\mathrm{S}_{4}\left(4-4,4 \mathrm{dS} \mathrm{m}^{-}\right.$ $\left.{ }^{1}\right)$. Para preparação das soluções salinas foi diluindo-se $\mathrm{NaCl}$ em água até a obtenção da condutividade elétrica almejada com o auxílio de um condutivímetro. As aplicações das dosagens de sal iniciaram quinze dias após o transplantio, adicionando-se $10 \mathrm{~mL}$ em cada vaso com o auxílio de um béquer, através de conhecimentos sobre pesquisas de MEDEIROS et al., (2003).

Após 90 dias, foram iniciadas as avaliações, quando as plantas já se apresentavam em tamanho ideal de uma planta adulta, atingindo estádio de maior valor comercial de acordo com a metodologia proposta por LESSA (2004). Dessa forma foi possível analisar: Altura das plantas (ALT): realizada com o auxílio de uma régua graduada, sendo os dados expressos em $\mathrm{cm}^{2}$; Comprimento da raiz $(\mathrm{CR})$ : realizada com o auxílio de uma régua graduada, desde o colo até o ponto máximo da raiz principal seguindo-se o eixo vertical $(\mathrm{cm})^{2}$; Peso Total $(\mathrm{g})$ : obtido através de uma balança de precisão semianalítica modelo BL-320H com três decimais de precisão $(0,001 \mathrm{~g})$; Matéria Fresca e Seca da parte aérea e da raiz respectivamente (MFPA/MFRA E MSPA/MSRA) expressos em $\mathrm{g}$, onde para obtenção da matéria seca as plantas foram colocadas para secar em estufa de circulação forçada a $80{ }^{\circ} \mathrm{C}$ até atingirem peso constante por um período de 48 horas. As pesagens foram realizadas em balança semianalítica, modelo $\mathrm{BL}-320 \mathrm{H}$ com três decimais de precisão $(0,001 \mathrm{~g})$; Número de Folhas (NF); Diâmetro da planta (DP): obtido a partir das extremidades do maior par de folha formado na planta, com o auxílio de uma régua milimetrada; Diâmetro e comprimento da $5^{\circ}$ folha (D5ํㅜㄹ $\mathrm{F}$ COMP5 $\left.{ }^{\mathrm{a}} \mathrm{F}\right)$ : com o auxílio de um paquímetro digital de precisão dados expressos em $(\mathrm{mm})$; Clorofila a (Chla) e Clorofila b (Chlb), mensurados através do equipamento portátil clorofilômetro MOD-SPAD; Diâmetro da Folha (DF), mensurados através de um paquímetro digital; Peso foliar total (PFT), realizado através de uma balança semianalítica.

Os resultados observados das variáveis analisadas foram submetidos à análise de variância, com auxílio do programa SISVAR® (FERREIRA, 2010). Na avaliação dos efeitos das doses utilizou-se a análise de regressão ao nível de $1 \%$ e $5 \%$ de probabilidade pelo teste $\mathrm{F}$ e no maior coeficiente de determinação $\left(R^{2}\right)$. Para a confecção dos gráficos foi utilizado o programa Microsoft Office Excel 2007 ®.

\section{RESULTADOS E DISCUSSÃO}

Analisando-se os resultados, pode-se observar que o resumo da análise de variância (Tabela 1) apresenta diferenças significantes a $5 \%$ de probabilidade pelo teste F para as características: peso total (PT), matéria fresca da parte aérea 
(MFPA) e para a massa seca da parte aérea (MSPA). Esses resultados indicam que elas apresentaram comportamentos semelhantes quanto à doses de cloreto de sódio ( $\mathrm{NaCl}$ ) aplicadas nos tratamentos, influenciando o desenvolvimento de das mudas de Kalanchoe (K. marmorata). Para as outras variáveis analisadas verificouse que não houve efeito significativo para os tratamentos utilizados.

TABELA 1 - Resumo da análise de variância para altura da planta (ALT), comprimento da raiz $(\mathrm{CR})$, peso total (PT), massa fresca da parte aérea (MFPA), massa fresca da raiz (MFRA), número de folhas (NF), diâmetro da planta (DP), diâmetro da $5^{\text {a }}$ folha (D5 $\left.5^{a}\right)$, comprimento da $5^{\text {a }}$ folha (COMP. $\left.5^{a} \mathrm{~F}\right)$, clorofila a (Chla), Clorofila b (Chlb), diâmetro de folha (DF), peso foliar total (PFT), massa seca daparte aérea (MSPA) e massa seca da raiz (MSR) das plantas de Kalanchoe (Kalanchoe marmorata) sob diferentes níveis de condutividade elétrica, Fortaleza-CE, 2014.

QUADRADO MÉDIO

\begin{tabular}{lcccccccccc}
\multicolumn{1}{c}{ FV } & GL & ALT & CR & PTOTAL & PFT & DF & NF & DP & D5F & COMP.5 F \\
\hline $\begin{array}{l}\text { DOSES } \\
\text { (D) }\end{array}$ & 4 & $2,33^{\mathrm{ns}}$ & $1,94^{\mathrm{ns}}$ & $26,09^{*}$ & $13,59^{*}$ & $3,46^{\mathrm{ns}}$ & 0,166 & $194,1^{\mathrm{ns}}$ & $16,44^{\mathrm{ns}}$ & $1,94^{\mathrm{ns}}$ \\
RESÍDUO & 20 & 0,83 & 1,63 & 3.73 & 1,748 & 2,21 & 0,014 & 58,88 & 11,03 & 0,53 \\
\hline CV(\%) & 22,96 & 22,96 & 20,24 & 26,8 & 40,5 & 14,87 & 9,47 & 28,38 & 26,11 & 25,31 \\
MÉDIA & 3,96 & 3,96 & 6,29 & 7,28 & 3,26 & 9,99 & 1,28 & 27,03 & 12,72 & 2,88 \\
\hline \multicolumn{7}{l}{ FV = Fonte de variação; GL = Grau de liberdade; CV = Coeficiente de variação; Significativo a 0,05 (*) e } \\
a 0,01 $\left(^{* *}\right)$ de probabilidade, respectivamente; ns - não significativo pelo teste F.
\end{tabular}

QUADRADO MÉDIO

\begin{tabular}{lccccccc}
\multicolumn{1}{c}{ FV } & GL & MFPA & MFRA & MSPA & MSRA & Chla & Chlb \\
\hline DOSES (D) & 4 & $27,53^{*}$ & $0,05^{\text {ns }}$ & $0,05^{*}$ & $0,001^{\text {ns }}$ & $13,49^{\text {ns }}$ & $1,82^{\text {ns }}$ \\
RESÍDUO & 20 & 5,16 & 0,02 & 0,009 & 0,003 & 11,43 & 0,66 \\
\hline CV(\%) & 22,96 & 33,06 & 37,29 & 36,04 & 42,19 & 15,59 & 20,05 \\
MÉDIA & 3,96 & 6,87 & 0,36 & 0,27 & 0,038 & 21,68 & 4,06 \\
\hline
\end{tabular}

FV = Fonte de variação; GL = Grau de liberdade; CV = Coeficiente de variação; Significativo a 0,05 (*) e a $0,01\left(^{* *}\right)$ de probabilidade, respectivamente; ns - não significativo pelo teste $\mathrm{F}$.

Para altura de plantas, não houve efeito significativo. A aplicação da maior dose de cloreto de sódio $(\mathrm{NaCl})$ proporcionou às plantas um efeito decrescente no desenvolvimento (Figura 01). Sob as diferentes concentrações de condutividade elétrica, observou-se que a altura (ALT) ajustou-se ao modelo linear de regressão. Pode-se notar que para as doses $S_{0}$ - controle $(0,0)$ as mudas de Kalanchoe apresentaram maior média $(4,44 \mathrm{~cm})$ e menor média quando submetidas à solução salina $\mathrm{S}_{4}\left(4-4,4 \mathrm{dS} \mathrm{m}^{-1}\right)$. De acordo com RIBEIRO (2009) A salinidade pode ser definida como a situação de excesso de sais solúveis, sódio trocável ou ambos em horizontes ou camada superficiais, afetando o desenvolvimento vegetal. Nesse sentido a presença de $\mathrm{NaCl}$ nos tecidos das plantas podem influenciar de forma negativa na expansão de suas células.

Outro fato que ainda pode ser mencionado de acordo com pesquisas de MOTA et al., (2006) é que condições adversas podem provocar o fechamento dos 
estômatos reduzindo a fotossíntese, e consequentemente a translocação de nutrientes da raiz para a parte aérea, reduzindo o alongamento celular.

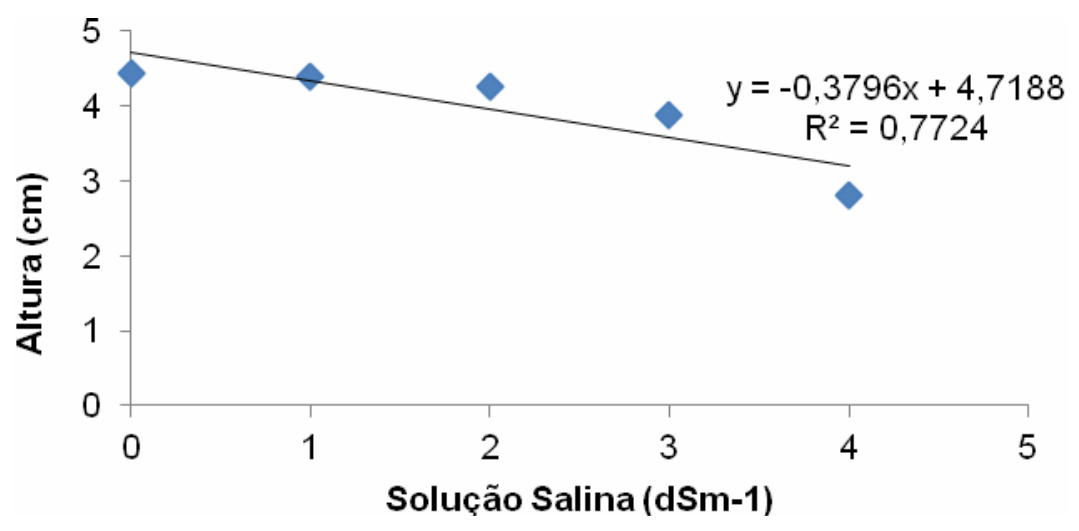

FIGURA 1 - Altura (ALT) das mudas de Kalanchoe (K. marmorata) cultivadas sob diferentes níveis de condutividade elétrica.

Segundo OLIVEIRA et al., (2010), a salinidade afeta o crescimento das plantas, inibindo tanto o processo de divisão como o de expansão celular. Dentre muitas respostas que as plantas podem apresentar quando se trata da presença de sais na água de irrigação, segundo TAIZ \& ZEIGER (2013) é o decréscimo no potencial hídrico da solução do solo a nível abaixo do necessário para que ocorra a absorção de água pelas células das raízes, impedindo, por conseguinte, a expansão celular.

Sobre o comprimento da raiz $(6,30 \mathrm{~cm})$, não houve diferença significativa para as soluções salinas utilizadas na pesquisa. Dessa forma, foi possível perceber o comportamento decrescente quanto ao aumento das doses ( $\mathrm{NaCl}$ ) utilizadas. OLIVEIRA et al., (2010) complementam afirmando que a salinidade reduz a condutividade hidráulica das raízes limitando o fluxo de água e sais para a parte aérea.

Com relação às variáveis: matéria fresca da raiz (MFRA) e a matéria seca da raiz (MSRA) não houve efeito significativo para os tratamentos analisados, apresentando uma resposta negativa quanto às soluções salinas. A salinidade segundo EPSTEIN \& BLOOM (2006) afeta negativamente a absorção de água pelas raízes, onde a presença de sais na solução do solo acarreta em uma diminuição do potencial hídrico externo. DIAS \& BLANCO (2010) acrescentam que o aumento da pressão osmótica causado pelo excesso de sais solúveis na solução do solo, bloqueia o mecanismo de sucção de água das plantas em processo denominado de seca fisiológica.

Sob o efeito de doses de salinidade ( $\mathrm{NaCl})$, para a variável MFPA, houve um ajustamento ao modelo linear de regressão, com comportamento decrescente. Observou-se que o maior valor médio observado $(8,99 \mathrm{~g})$ para a massa fresca da parte aérea foi nas plantas controle $S_{0}$ - controle $(0,0)$, ou seja, na ausência de salinidade. O menor valor médio $(3,33 \mathrm{~g})$ para MFPA foi para as plantas que receberam a maior dose salina $(\mathrm{NaCl})$ (Figura 02$)$. Por esses resultados, constatou- 
se que mudas de $k$. marmorata não respondem favoravelmente ao tratamento com doses salinas, pois observa-se que a medida que há um aumento da dose salina, ocorre um decréscimo da matéria fresca da parte aérea.

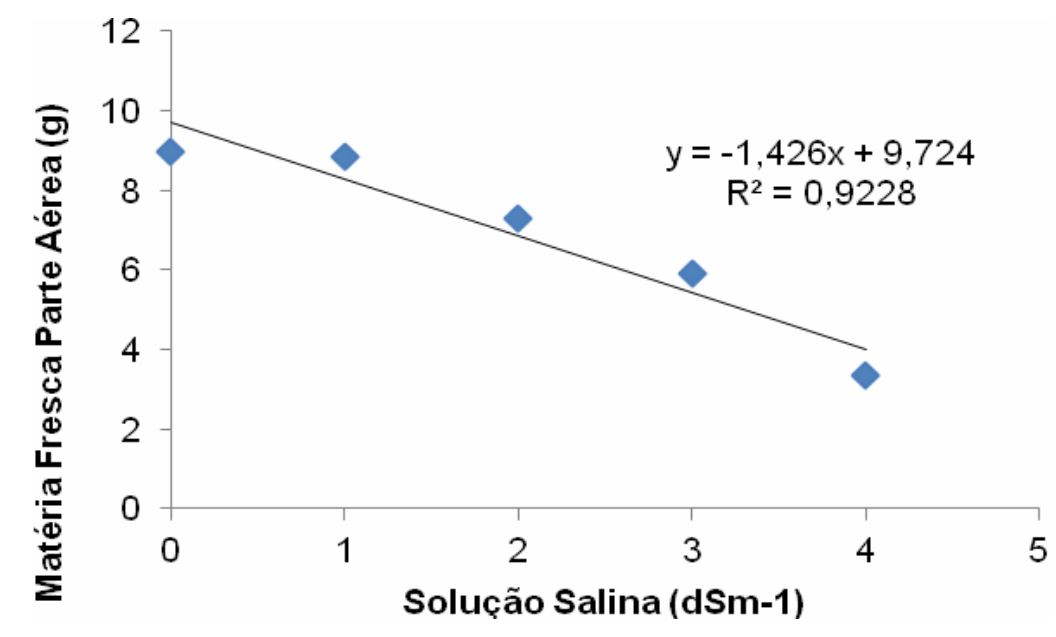

FIGURA 2 - Matéria Fresca da Parte Aérea (MFPA) das mudas de Kalanchoe (K. marmorata) cultivadas sob diferentes níveis de condutividade elétrica.

O acúmulo excessivo de sais pode levar à morte dos tecidos, órgãos e mesmo da planta inteira. Isso ocorre, em grande parte, devido aos distúrbios provocados pelos efeitos dos íons $\mathrm{Na}+\mathrm{e} \mathrm{Cl}$ - acumulado nas células, os quais afetam vários processos metabólicos (OLIVEIRA et al., 2010). FARIAS et al., (2009) ressaltam que os efeitos do excesso de sais solúveis na solução do solo, provocam redução do desenvolvimento vegetal, promovendo distúrbios fisiológicos.

O peso total fresco das mudas de Kalanchoe marmorata, quando se refere ao acréscimo de sais na água da irrigação respondeu de forma negativa (Figura 03), onde é possível observar que o menor peso apresentado pela espécie está associado a maior dose de $\mathrm{NaCl} \mathrm{S}_{4}\left(4-4,4 \mathrm{dS} \mathrm{m}^{-1}\right)$ utilizada.

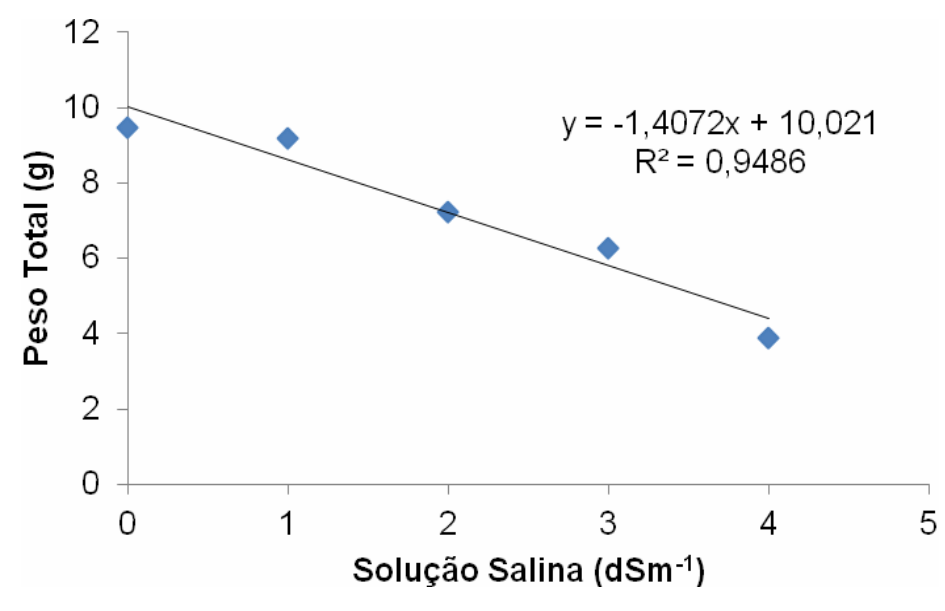

FIGURA 3 - Peso Total Fresco das mudas de Kalanchoe $(K$. marmorata) cultivadas sob diferentes níveis de condutividade elétrica. 
Segundo pesquisas realizadas por SOUSA et al., (2010), em várias espécies de Kalanchoe, o autor afirma que em função do crescimento vegetativo é possível avaliar a biomassa verde, através da retirada da planta inteira do vaso, sem danificar as raízes, onde assim se torna possível obter dados referentes ao peso total da planta, que pode estar associado diretamente a disponibilidade e a qualidade da água presente no substrato para o desenvolvimento adequado da espécie.

HOLANDA et al. (2010) complementam que para a maioria das culturas isso ocorre, quando a condutividade elétrica do extrato de saturação é igual ou superior a $2 \mathrm{dSm}^{-1}$, justificando o comportamento negativo da espécie de Kalanchoe quando submetido as doses crescentes de $\mathrm{NaCl}$ na solução aquosa da irrigação.

O aumento da matéria fresca das plantas está diretamente relacionado com o crescimento e desenvolvimento das espécies. Para tanto, TAIZ \& ZEIGER (2013) afirmam que o primeiro efeito da salinidade no desenvolvimento das plantas é a redução no crescimento, provocado pelo decréscimo no potencial hídrico da solução do solo, dificultando consequentemente, a expansão celular, devido ao estresse hídrico ocasionado na planta inteira.

No que se refere ao diâmetro da planta e comprimento da $5^{\text {a }}$ folha do $K$. marmorata sob o efeito de doses de salinidade $(\mathrm{NaCl})$, para as variáveis mencionadas acima, houve um ajustamento ao modelo linear de regressão, com comportamento decrescente, onde com o aumento das doses há uma redução do diâmetro da planta e do comprimento da $5^{\mathrm{a}}$ folha, que já se encontrava distendida.

Avaliando-se o comprimento da $5^{\text {a }}$ folha (Figura 04) é possível ressaltar que apesar do comportamento decrescente para as soluções salinas utilizadas na pesquisa, pode-se observar que o k. marmorata apresentou uma maior média $(3,42$ $\mathrm{cm})$ correspondente a expansão da $5^{\text {a }}$ folha quando aplicada a solução salina $S_{1}$ (1$\left.1,3 \mathrm{dS} \mathrm{m}^{-1}\right)$. No entanto a solução salina de maior concentração de sais $\mathrm{S}_{4}(4-4,4 \mathrm{dS}$ $\left.\mathrm{m}^{-1}\right)$ apresentou a menor média $(1,82 \mathrm{~cm})$ para variável analisada, onde é possível concluir que o aumento de doses não apresentou resultados satisfatórios quando se trata da expansão foliar, fato que poderia prejudicar o aspecto visual da espécie para comercialização.
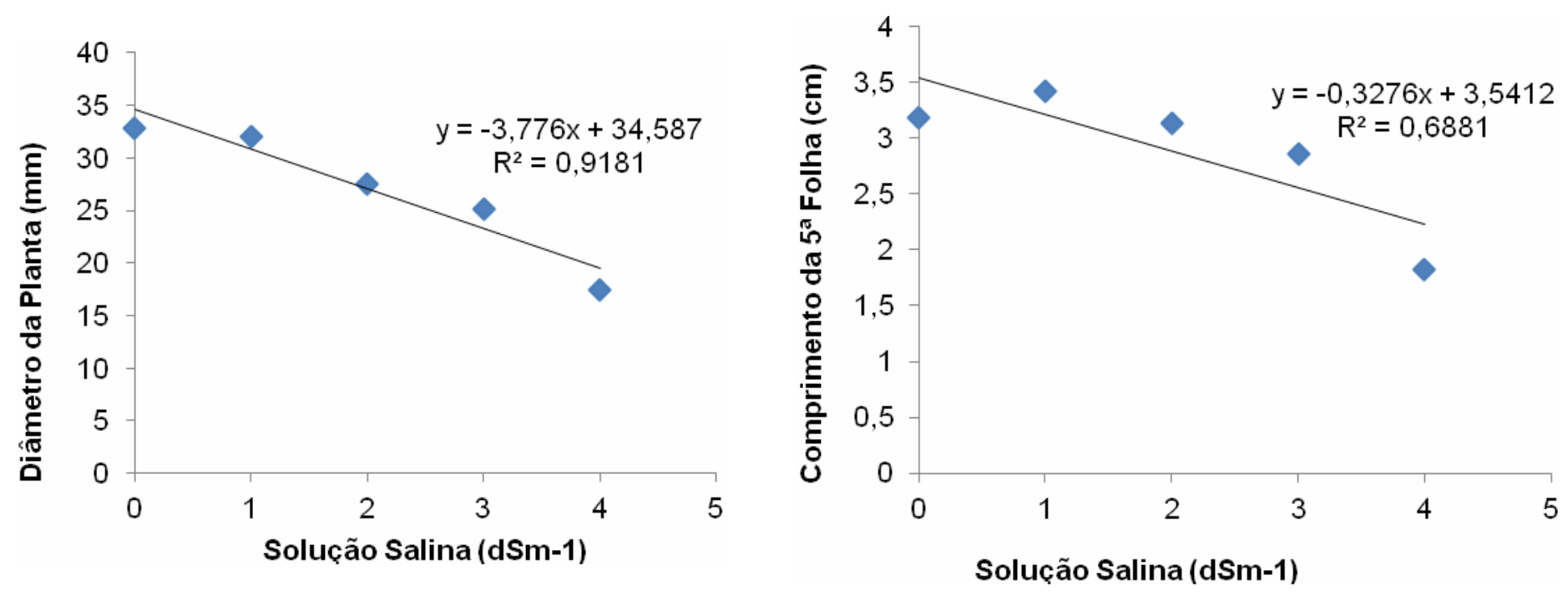

FIGURA 4 - Diâmetro da Planta (DP) e Comprimento da $5^{\text {a }}$ Folha (COMP. $5^{\text {a }}$ F) das mudas de Kalanchoe (K. marmorata) cultivadas sob diferentes níveis de condutividade elétrica. 
O fato da expansão foliar ter sido considerada maior quando aplicada a solução salina S1, pode ser explicada segundo PARIDA \& DAS (2005) devido a algumas plantas que estão sob condições de estresse salino, a espessura do mesofilo foliar aumenta em decorrência ao acréscimo no número e comprimento das células paliçádicas e no número de camadas de células paliçádicas e esponjosas, como também a aumentos na quantidade de água por área foliar, ou suculência foliar.

O 5o par de folhas de Kalanchoe marmorata apresenta-se em destaque na estrutura da planta, conferindo um aspecto visual harmonioso, contribuindo para seu valor comercial. De acordo com estudos de LESSA (2004) essas folhas caracterizam-se por serem maiores em diâmetro em relação aos demais pares e assim pode conferir a planta um aspecto visual de maior ostentação.

Para a quantificação da clorofila a (Chla) e da clorofila b (Chlb) foi possível observar que o aumento das concentrações de sal nas soluções que foram aplicadas nos vasos, resultaram em quantitativos cada vez mais baixos de clorofila a e b. MOTA et al.,(2006) ressaltam que a elevada concentração de sais na solução do solo pode ocasionar uma perda da permeabilidade da membrana citoplasmática, além de influenciar no processo de fotossíntese, já que o conteúdo da clorofila sofre uma redução. O mesmo autor ainda destaca que as folhas podem apresentar uma coloração verde azulada escura, maior espessura e serosidade.

O peso foliar total da espécie em estudo apresentou um comportamento decrescente para os diferentes níveis de condutividade elétricas utilizados, ressaltando que o aumento de sais na água da irrigação pode ter prejudicado de forma real o desenvolvimento da espécie, principalmente no que diz respeito na formação das suas folhas (Figura 05).

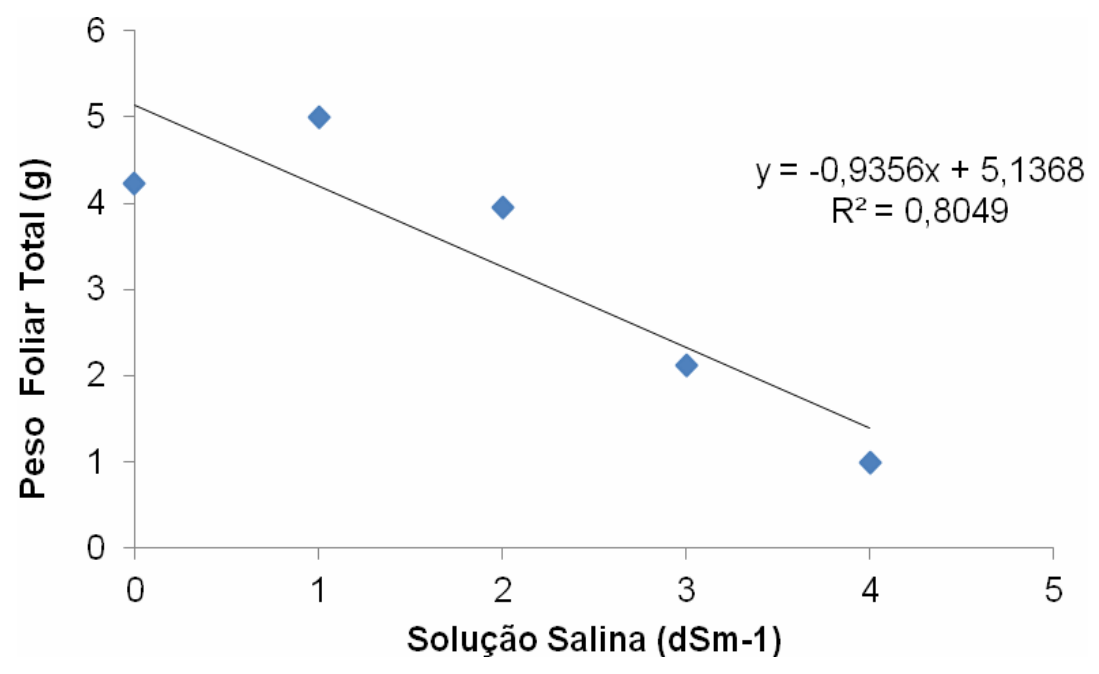

FIGURA 5 - Peso Foliar Total $(g)$ das mudas de Kalanchoe $(K$. marmorata) cultivadas sob diferentes níveis de condutividade elétrica.

Algumas plantas sob condições de estresse salino apresentam a espessura do mesofilo foliar mais elevada, devido ao aumento no número e comprimento das células paliçádicas e no número de camadas de células paliçádicas e esponjosas (PARIDA \& DAS., 2005). Conforme pesquisas desses autores, as respostas das plantas à salinidade são muitas vezes acompanhadas por alterações morfológicas e 
anatômicas. Desse modo o peso foliar, que foi apresentando uma queda com relação ao aumento de doses de Nacl pode ser explicado por tais afirmações com base nos autores mencionados, onde a estrutura anatômica da planta é modificada sob condições de estresse salino.

Para a matéria seca da parte aérea (MSPA), as mudas de K. marmorata apresentaram ajustamento ao modelo linear de regressão com maior peso médio observado $(0,37 \mathrm{~g})$ de MSPA para as plantas que não receberam nenhuma dose de sal (controle). No nível máximo de salinidade $\mathrm{S}_{4}\left(4-4,4 \mathrm{dS} \mathrm{m}^{-1}\right)$, foi possível verificar as reduções na matéria seca com os menores valores médios observados $(0,13 \mathrm{~g})$ (Figura 06). Resultados semelhantes foram encontrados por CAVALCANTE et al., (2010) estes autores afirmam que a produção da massa seca da parte aérea foi estatisticamente reduzida em aproximadamente $36 \%$ da CE de $2,1 \mathrm{dS}$ m-1 para a de 4,9 dS m-1.

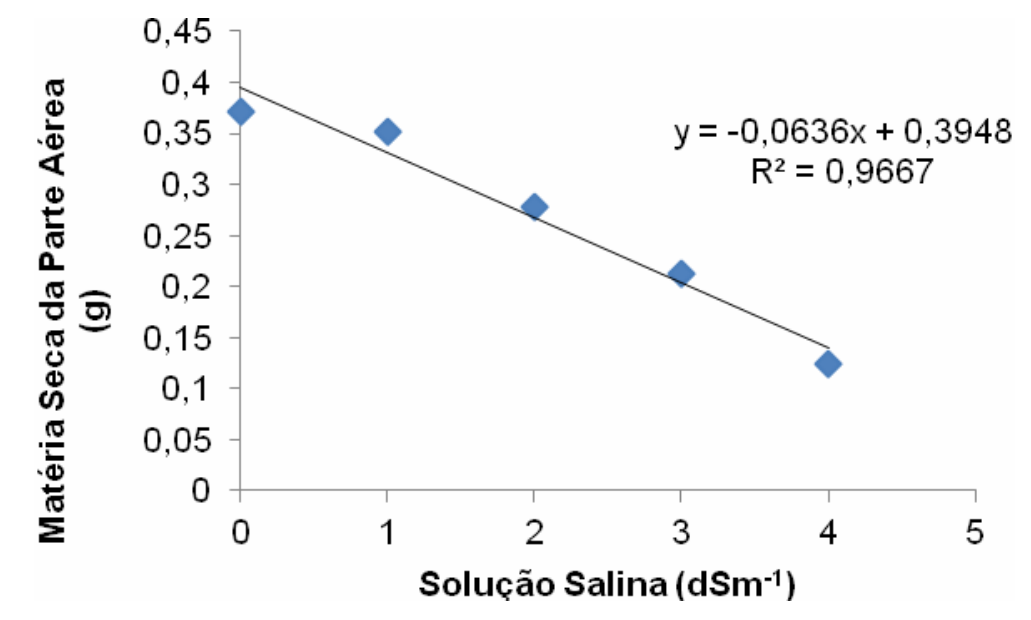

FIGURA 6 - Matéria Seca da Parte Aérea (MFPA) das mudas de Kalanchoe (K. marmorata) cultivadas sob diferentes níveis de condutividade elétrica.

\section{CONCLUSÕES}

As soluções salinas interferem de forma significativa no desenvolvimento de mudas de Kalanchoe ( $K$. marmorata), tornando-se mais deletéria com o aumento das concentrações de sais que foram aplicadas nos vasos pote 6 . Nas condições do experimento as mudas responderam de forma negativa as soluções salinas utilizadas.

\section{REFERÊNCIAS}

CAVALCANTE, L. F.; CAVALCANTE, M. Z. B.; PIVETTA, K. F. L.; CAVALCANTE, I. H. L. CAVALCANTE, L. F.; BELLINGIERI, P. A.; CAMPOS, M. C.C. Condutividade elétrica da solução nutritiva para o cultivo de crisântemos em vaso. Revista Brasileiro de Ciência do Solo, 34: 747-756, 2010.

BUSTAMANTE, P. M. A. C. A fruticultura no Brasil e no Vale do São Francisco: Vantagens e desafios. Revista Econômica do Nordeste, v.40, p.153-171, 2009. 
DIAS, N. D.; BLANCO, F. F. Efeitos dos sais no solo e na planta. In: GHEYI, H. R.; DIAS,N.S.; LACERDA,C.F. Manejo da salinidade na agricultura: Estudos básicos e aplicados. Fortaleza: Instituto Nacional de Ciência e Tecnologia em Salinidade. p. 129-140, 2010.

EPSTEIN, E.; BLOOM, A. J. Nutrição mineral de plantas: princípios e perspectivas. Londrina: Editora Planta. 403p, 2006.

FARIAS, S. G. G. Estresse salino no crescimento inicial e nutrição mineral de Gliricídia (Gliricidia sepium (Jacq.) Kunt ex Steud) em solução nutritiva. Revista Brasileira de Ciência do Solo, v. 33, p. 1499-1505, 2009.

FERREIRA, D. F. SISVAR - Sistema de análise de variância. Versão 5.3. LavrasMG: UFLA, 2010.

HOLANDA, J. S.; AMORIM, J. R. A.; FERREIRA NETO, M.; HOLANDA, A. C. Qualidade da água para irrigação. In: GHEYI, H. R.; DIAS, N. S.; LACERDA, C. F. Manejo da salinidade na agricultura: Estudos básicos e aplicados. Fortaleza: Instituto Nacional de Ciência e Tecnologia em Salinidade, 2010. p. 43-61.

IBRAFLOR. Instituto Brasileiro de Floricultura. Mercado interno e Plano Safra 2013.1. Disponível em: <http://www.ibraflor.com/ns_mer_interno.php>. Acesso em: 04 set. 2013.

KAMPF, A.; N. Horticultura e Floricultura. In: Produção comercial de plantas ornamentais. Guaíba: Agropecuária, 2000. P. 15-23.

KAMPF, A. N. Produção comercial de plantas ornamentais. 2 edição. Guaíba agrolivros. p. 72 - 89, 2005.

KÖPPEN, W. Climatologia: con un estudio de los climas de la tierra. México: Fondo de Cultura Econômica, 478p., 1948

LESSA, M. A. Efeito de diferentes substratos sobre a propagação e desenvolvimento de duas espécies de Crassulaceae. In: ENCONTR0 NACIONAL SOBRE SUBSTRATOS PARA PLANTAS, 4., 2004, Viçosa, MG: UFV, 2004. p. 371.

MEDEIROS, J.F.; LISBOA, R.A.; OLIVEIRA, M.; SILVA JÚNIOR, M.J.; ALVES, L.P. Caracterização das águas usadas para irrigação na área produtora de melão da Chapada do Apodi. Revista Brasileira de Engenharia Agrícola e Ambiental, v. 07, n. 03, p. 469-472, 2003.

MOTA, P. R. A.; BOAS, R. L. V.; SOUSA, V. F. Concentração de sais da solução avaliada pela condutividade elétrica na zona radicular do crisântemo sob irrigação por gotejamento. Irriga, Botucatu, v. 11, n. 4, p. 532 - 542, outrubro-dezembro, 2006. 
NEVES, A.L.R.; LACERDAL, C.F.; GUIMARÃES, F.V.A.; HERNADEZ, F.F.F.; SILVA, F.B.; PRISCO, J.T.; GHEYI, H.R. Acumulação de biomassa e extração de nutrientes por plantas de feijão-de-corda irrigadas com água salina em diferentes estádios de desenvolvimento. Ciência Rural, v. 39, n. 03, p. 758-765, 2009.

OLIVEIRA, A. B. de.; FILHO; E. G.; FILHO, J.E. O Problema da salinidade na agricultura $e$ as adaptações das plantas ao estresse salino. ENCICLOPÉDIA BIOSFERA, Centro Científico Conhecer - Goiânia, vol.6, N.11; p. 1- 16. 2010.

PARIDA, A. K.; DAS, A. B. Salt tolerance and salinity effects on plants: a review.Ecotoxicology and Environmental Safety, New York, v.60, n.3, p.324-349. 2005.

RIBEIRO, M. R. Química dos solos salinos e sódicos. In: MELO, V. F.; ALLEONI, L. R. F. (ed.). Química e mineralogia do solo. Parte II - Aplicações. Viçosa: Sociedade Brasileira de Ciência do Solo. p. 449-484, 2009.

SANTOS JÚNIOR, J. A.; GHEYI, H. R.; GUEDES FILHO, D. H.; DIAS, N. DA S.; SOARES, F. A. L. Cultivo de girassol em sistema hidropônico sob diferentes níveis de salinidade. Revista Ciência Agronômica, v.42, p.842-849, 2011.

SOUSA, A. B. O.; BEZERRA, M. A. Desenvolvimento de mudas de Portulacaria afra. Jacq. oriundas de diferentes explantes e irrigadas com água salina. Simpósio Brasileiro de Salinidade, outubro de 2010, Fortaleza, CE, Brasil

TAIZ, L; ZEIGER, E. Fisiologia vegetal. 4ed. Porto Alegre: Artmed, 2013.

TAKANE, R. J; PIVETTA, K. F. L; YANAGISAWA, S. S. Cultivo técnico de cactos e suculentas ornamentais. 1. ed. Fortaleza: GrafHouse, 2009. 